\title{
A Preliminary Study of Organizational Leadership Development
}

\author{
Cheng Yun,Wang Linchang Wuhan University \\ Economics and management school \\ Wuhan University \\ Wuhan, People's Republic of China \\ E-mail: chengyun@huawei.com,wlc87664977@126.com
}

\begin{abstract}
While organizations are running in a more complicated and ever-changing environment, the leadership development should not focus on improving the management skills of the few managerial individuals in the organization only, but cover the whole organization to develop all members collective capabilities which are needed to complete collective leading tasks. The sole focus on management skills should be expanded to the patterns of connectivity within the organization as well as organizational culture, organizational structure, rules and processes. Organizational leadership development should aim to assimilate or improve organizational values and management philosophies, communicate expectations and requirements for different roles of the organization to implement strategies, or communicate the necessity and specific requirements of the current major transformations in the organization.
\end{abstract}

Keywords-leadership; organizational leadership development; individual leadership development

\section{DEFINITION OF ORGANIZATIONAL LEADERSHIP DEVELOPMENT}

Organizational leadership development refers to the systematic measures that are adopted by an organization in the full dimension to develop the collective capabilities needed to achieve the collective leadership, while coping with the challenges of the organization. As organizations are facing a more complicated and ever-changing environment, the individuals at the leaders' positions cannot handle the leading tasks independently, but have to rely on teamwork to complete such leading tasks as determining the direction of the organization, establishing joint efforts, and encouraging accountability (McCauley, 2004). With the social development, the individuals within an organization are less attached and loyal to the organization, while having a tendency of pursuing self-management and shared leadership. Their resistance to being ordered, arranged, and monitored has reduced the effectiveness of those individuals who take the managerial positions within the organization. Under such a circumstance, the focus of leadership or leadership development has shifted from individual leaders to the entire organization, emphasizing the collective capabilities of the organization to rise to challenges and achieve transformations. The collective capabilities include the leading capabilities of the individuals who take a leading position in the organization, effectiveness in rising to organizational challenges of other individuals who do not take a leading position, and factors that affect the organization in responding to changes and achieving transformations, e.g. faith in teamwork and combination method. That's where the concept of organizational leadership and organizational leadership development originate. The original activities that focus on individuals at leading positions and develop their capabilities to make them competent in their leading roles are defined as leader development or individual leadership development. As for the activities orienting towards the entire organization to develop the collective capabilities required by completing the collective leading tasks, we call them organizational leadership development. The basic leading tasks in collective working situations include determining the direction in a fast-changing and uncertain environment, effectively integrating the resources required to achieve organizational goals, and keeping members loyal and committed to the organization through incentives and encouragement. As a collective capability, leadership is not simple addition of all individual leadership within the organization. It also involves an effective motivation mechanism to facilitate all stakeholders to complete leading tasks via the mutual effect of different factors, e.g. individuals, teams, circumstance, and more, in the organization.

The table I describes the changes to the understanding of leaders and leadership (Wen Maowei, 2011).

\section{INSPIRATION OF THE CONCEPT OF ORGANIZATIONAL LEADERSHIP DEVELOPMENT FOR ACTUAL WORK}

Getting in line with the current social development trends, the concept of organizational leadership development describes more explicitly the essence of leadership development, broadens the horizon of leadership studies, and brings the inspiration of leadership development practices.

A. The group included in leadership development should be extended from the individual leaders to all members of an organization.

From a traditional perspective, leadership development usually refers to improving the required knowledge, skills, or attitudes of those individual leaders in making them competent in their managerial positions through ways such as on-the-job practice, coaching, and 360 degree feedback. 
Table I. Changes to the understanding of leaders and leadership

\begin{tabular}{|c|c|c|}
\hline & Traditional & Current \\
\hline Leaders & $\begin{array}{l}\text { Individuals who take a formal } \\
\text { leading position }\end{array}$ & All members of an organization \\
\hline Leadership & $\begin{array}{l}\text { Exclusive wealth of an } \\
\text { individual (leading talent or } \\
\text { capabilities) }\end{array}$ & $\begin{array}{l}\text { Collective activities of all organization members. These } \\
\text { activities focus on the concepts and methods developed } \\
\text { through group interactions. Guided by organizational vision } \\
\text { that contains common values, such activities put the } \\
\text { emphasis on attainment of organizational goals through } \\
\text { "unlocking" the organization members' leadership and their } \\
\text { coordinated interactions. }\end{array}$ \\
\hline $\begin{array}{l}\text { Leadership } \\
\text { effectiveness }\end{array}$ & $\begin{array}{l}\text { Product of a specific part (e.g., } \\
\text { leaders) within a system }\end{array}$ & $\begin{array}{l}\text { Product of links and relationships among all components of } \\
\text { a system }\end{array}$ \\
\hline $\begin{array}{l}\text { Leadership } \\
\text { development }\end{array}$ & $\begin{array}{l}\text { Oriented towards the individuals } \\
\text { who take a formal leading } \\
\text { position, aims at helping them } \\
\text { become competent in their } \\
\text { leading roles. }\end{array}$ & $\begin{array}{l}\text { Oriented towards the entire organization, aims at developing } \\
\text { the collective capabilities of the organization members who } \\
\text { are tasked with leading the organization. }\end{array}$ \\
\hline
\end{tabular}

Currently, most papers and books on leadership development concentrate on the leader development. In actual work, some leadership development programs or courses are aimed at "removing managers' weak links in their capabilities" or "duplicating 'DNA' from successful practices". However, even if these programs or courses get high scores in satisfaction assessment for their enriched forms and delicate design, their expected effects cannot be achieved at most of the time. The reason for this is that the factors that influence the effectiveness of behaviors of individual leaders include the leaders' personalities, positions, and management capabilities; their followers' values, capabilities, and willingness; their teams' regulations and cohesive; as well as such situational factors as tasks, pressure, and environment. Improving managers' competency alone often has limited effect on improving the leadership effectiveness of the entire organization.

From the perspective of organizational leadership, leadership effectiveness and organization goals are attained through collective activities of organization members, "unlocking" leadership of organization members, and their coordinated interaction. Therefore, the emphasis of the organizational leadership development is not on individual leaders only, but on all members of the organization instead, with improving the individual capabilities and the way they interact with each other in order to fulfill leading tasks.

B. The content of leadership development should not be limited to the capability improvement of individual leaders, but extend to the enrichment of connectivity patterns within the organization and factors like organizational culture, organizational structure, rules and processes.

Improvement of all members within an organization in their individual leading capabilities does not necessarily mean that the organization can complete such leading tasks as "determining the direction of the organization, establishing joint efforts, and encouraging accountability" and successfully attain organizational goals. The patterns of connectivity within the organization, e.g. organizational culture, organizational structure, rules and processes are vital for the organization to effectively cope with the complicated challenges.

Getting more organization members involved in completing leading tasks through cooperation in more diversified ways increases the possibility for innovative organization members who are capable in generating necessary changes to make better use of their influence in leading tasks. In addition, these members can also get more sensitive and responsive to environmental changes and establish joint efforts more promptly to address various complicated challenges, thus completing leading tasks more effectively. Therefore, the leadership development requires the efforts on exploring and extending the social relationships, the enhancement of the delicate and rich social network within an organization. In particular, it means keeping closer ties among different entities, establishing subtle and enriched social connections within the organization, and increasing the social capitals of the organization, thereby making collective activities more possible and effective. Detailed solutions include establishing and expanding a network that connects the isolated individuals through an IT platform; finding more common ground or perceptions through enriched communication; and deepening the interactions among entities of the network in enriched ways such as discussion on common concerns in virtual communities.

The individuals and teams connect in some methods to form organizations, which are often demonstrated in organizational cultures, management philosophies, organizational structures, processes, and various policies. These factors have a tremendous impact, either a barrier or an effective support and assistance, on an organization's tackling with complicated challenges and completing leading 
tasks. Therefore, the leadership development shall also incorporate the above-mentioned factors, and organizations should deliberately concentrate its efforts on transforming its culture, improving its structure and processes, adjusting organization policies and regulations as to facilitate the organization to effectively complete leading tasks and achieve goals.

The aforesaid opinions are verified by the studies on leadership development practices. Senior expert, like Jay A. Conger, indicates that the leadership development practices for enterprises fall into three categories. The first is leader development, with the focus on promoting the basic viewpoints and leading skills of individual leaders; the second is assimilation of corporate philosophies, i.e. assimilating managers at all levels into the enterprise's management philosophies, values, and missions; the third is promotion and acceleration of important strategic transformations or enterprise innovations. At present, the practices of leadership development are moving towards the latter two directions, i.e. more practices are oriented towards assimilation of corporate philosophies and acceleration of strategic transformations. The leadership development programs designed to improve leaders' leading skills are gradually disappearing (Conger, 1999).

\section{Leadership development measures should not be limited to training programs, but extended to a variety of organizational development measures as needed.}

The commonly adopted measures to develop leadership are on-the-job practice, short-term experience, skill training courses or programs, coaching, etc. These measures attach much importance to improvement of participants' management skills, organization knowledge, work experience, and weakness overcoming(Byham, 2002), which makes little contribution to enrich the patterns of connectivity within the organization or generate direct value in improving organizational culture, management philosophies, organizational structure, rules and processes. However, the patterns of connectivity within the organization and the organizational methods mentioned above have a key impact on the organization in effectively tackling complicated challenges and completing leading tasks. Under most of the circumstances, these factors are more important than the "management skills, organization knowledge, work experience, and weakness overcoming" of organization members. The measures to develop organizational leadership should be selected in compliance with the organizational development methodology. To identify problems in meeting complicated challenges and completing leading tasks, the organization should adopt multiple measures comprehensively, e.g. encouraging innovations by adjusting performance appraisal policies and setting up informal crossfunctional work groups at all levels to enhance the connections of members within the organization.

\section{IMPLEMENTATION OF ORGANIZATIONAL LEADERSHIP} DEVELOPMENT

From the new perspective, distinction between leadership development and organizational development blurs and these two concepts are highly overlapped to some extent. Organizational leadership development seems to be related to every aspect of an organization. From the perspective of 7S model, all the six factors (structure, system, skill, style, staff, and shared vision) except "strategy" are included into the scope of organizational leadership development. The extended scope makes it more difficult to develop organizational leadership and brings about new challenges to the actual design and implementation of leadership development programs. This is the reason why although many organizations have already realized the limitation of leader development on the improvement of organizational performance, they still stick to the traditional practice to focus leadership development on the skill training for leaders.

The implementation of organizational leadership development means to adopt intervention measures to enhance the collective capabilities required by completing collective leading tasks when tackling the existing or upcoming challenges. In order to guarantee the efficiency of development activities, the organization may: firstly, put the emphasis on the requirements to successfully implement transformation or goals at the strategic level of the organization instead of capability improvement of only a few managers. Secondly, adopt comprehensive measures and promote such measures systematically from the aspects of organizational culture, structure, rules and process, and employee capability to tackle the challenges.

Organizational leadership development practices usually take the form of leadership development programs. To meet the requirements on achieving transformations or goals at the organization's strategic level, those programs can focus on the following aspects to produce practical results.

\section{A. Assimilate or improve organizational values and management philosophies.}

Values and management philosophies are the synthesis of all kinds of measures to integrate individuals of an organization, and serve as a guiding principle for developing organization processes, systems, and policies. It decides how the entire organization to address external challenges and has in-depth influence on the continued performance of the organization. Such influence could be positive or negative. Positive influence can facilitate the attainment of current goals and boost the long-term business growth of the organization, while negative influence may hinder the two factors mentioned above as well as the handling of complicated environment (Kotter, 1992). If leadership development programs can function well in the assimilation or improvement of organizational values and management philosophies, they will bring about far-reaching influence to the organization.

The organizational leadership development program influences organizational values and management philosophies in two ways. Firstly, an organization may take a 
series of measures to assimilate values and management philosophies that are conducive to addressing organizational challenges, thus forming a consistent perception at all levels within this organization. For example, an organization may collect and summarize case studies compliant with its organizational values and management philosophies and disseminate these case studies across the organization through workshops and other methods. An organization may also develop personnel selection, appraisal, and incentive systems that encourage behaviors aligned with its organizational values and management philosophies. At the management level, managers may be required to practice what the organization promotes and to thoroughly discuss the organizational values and management philosophies with employees. This requirement has been fully reflected in Noel M. Tichy's "virtuous teaching cycle" (Tichy, 2002), which indicates that developing teachable points of view about concepts and values at its leadership level can build an environment where supervisors at all levels interact with their subordinates to communicate these teaching opinions. As such, these teachable points of view are fully exchanged between supervisors and subordinates, so that every member of this enterprise can absorb them. Secondly, through collective workshops or discussions in internal virtual communities, the organizational leadership development program can bring to light the explicit or potential crisis beneath the organizational values and management philosophies that set barriers for the organization to addressing current challenges, fulfilling leading tasks, and achieving organizational goals. As a result, an extensive dialog about values and management philosophies will occur at all levels. During this dialog, negative elements beneath the organizational values and management philosophies will be eliminated, and new factors conducive to a shared perception and commitments will be created, so as to promote the refinement of the organizational values and management philosophies.

\section{B. Convey expectations and requirements for all roles in an organization so as to implement strategies.}

As the business environment changes fast, an organization's expectations and requirements for its members change accordingly. To ensure effective implementation of business strategies, the implementation efforts of upper and lower levels must be aligned. The organizational leadership development program conveys an organization's expectations and requirements for all of its members through multiple methods to ensure strategy fulfillment. This program also clarifies all members' responsibilities in line with the current business goals. In the course of organizational transformation, this program encourages all members to proactively and closely work with each other and devote themselves to implementing and supporting organizational strategies.

Clear expectations and requirements for each role should include, but are not limited to, the following items: current business challenges facing the organization, organizational responsibilities shouldered by each role; key business activities required to fulfill these responsibilities; common problems in performing these key business activities; and successful practices. We can convey expectations and requirements through collective workshops, coaching, or self-learning on case studies.

\section{Communicate the necessity and specific requirements of a key organizational transformation to gain support.}

Divided from the management development discipline, leadership development aims to improve an organization's ability to anticipate and respond to future challenges and to conduct effective transformations (Wen Maowei, 2008). In a changing environment, transformation has become a ordinary state of every organization. An organizational transformation in essence is to transform people. Any adjustment to an organization's business directions, strategies, or internal management cannot be achieved without sufficient communication about transformation necessity and specific requirements among staff at all levels. The organizational leadership development program is closely related to key transformations and has become part of the transformation program. It contributes to transformation programs by empowering organizations to address complex challenges and respond to transformations.

During the specific execution of such leadership development programs, appropriate collective workshops can be designed or internal active virtual communities can be leveraged to communicate with all members about a variety of issues, including the necessity and urgency of key transformations, progress of the transformation, and specific requirements for all members. All stakeholders' feedback on the transformation will be reported to decision makers. These efforts can bring about more extensive, profound, and comprehensive communication within an organization, which promotes the smooth evolvement of the transformation.

\section{REFERENCES}

[1] C. D. McCauley, and E. Van Velsor (eds.), The Center for Creative Leadership Handbook of Leadership Development (2nd ed.), San Francisco: Jossey- Bass, 2004, pp20-26.

[2] Conger Jay A. and Benjamin Beth, Building Leaders: How Successful Companies Develop the Next Generation, San Francisco: Jossey-Bass, 1999, pp1-26.

[3] John P. Kotter, and James L. Heskett, Corporate Culture and Performance, New York:THE FREE PRESS, 1992. pp3-14.

[4] Noel M. Tichy and Nancy Cardwell, The Cycle of Leadership: How Great Leaders Teach Their Companies to Win, New York: Harper Business, U.S. 2002, pp196-223.

[5] Wen Maowei, Leadership Development of Contemporary American and British Organizations: Theory and Practice, Hangzhou: Zhejiang University Press, 2011, pp56-73.

[6] Wen Maowei, Ongoing Changes: Seven Characteristics of Western Organizational Leadership Development, Human Resource development of China, 2008 (10), pp32-36.

[7] William C. Byham, Audrey B. Smith, and Matthew J. Paese, Grow Your Own Leaders: How to Identify, Develop, and Retain Leadership Talent, Upper Saddle River: Financial Times Prentice Hall, 2002, pp175-186. 